Journal of Sustainable Development of Transport and Logistics

journal home page: https://jsdtl.sciview.net

Shelton, L., \& Martin, P. T. (2021). How does the value of time influence road user costs

during work zone closures? A case study in El Paso, Texas, using simulation-based modeling methods. Journal of Sustainable Development of Transport and Logistics, 6(1), 18-31.

doi:10.14254/jsdtl.2021.6-1.2.

\title{
How does the value of time influence road user costs during work zone closures? A case study in El Paso, Texas, using simulation-based modeling methods
}

\author{
Jeffrey Shelton *(D), Peter T. Martin ** \\ ${ }^{*}$ Multi-Resolution Modeling, Texas A\&M Transportation Institute, El Paso, Texas \\ J-Shelton@tti.tamu.edu \\ ${ }^{* *}$ Department of Civil Engineering, New Mexico State University, Las Cruces, New Mexico \\ wales@nmsu.edu
}

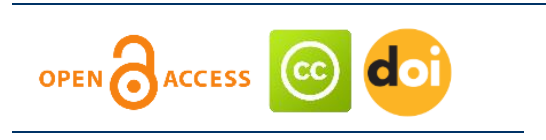

Article history:

Received: March 05, 2021

1st Revision: March 15, 2021

Accepted: April 12, 2021

\section{DOI:}

10.14254/jsdtl.2021.6-1.2
Abstract: It is becoming standard practice for many departments of transportation (DOTs) to use incentive/disincentive clauses (also known as road user costs) with contractors to stay on or ahead of schedule. These road user costs are clauses that DOTs use to calculate a monetary amount to encourage contractors to complete work prior to milestone dates and/or limit the time specified on the contract. The monetary amounts are typically vehicle operating costs and vehicle delay costs encumbered by highway users resulting from construction, maintenance, or rehabilitation activity. In this paper, we propose an innovative way of calculating these costs using varied values of time based on trip purpose and departure time. In addition, we use advanced pre-trip and en route traveler information to determine the influence it has on route choice. Several scenarios are modeled using an advanced, simulation-based dynamic traffic assignment model. The goal of this paper is to identify the governing factors that contribute to road use costs by determining different approaches to derive the value one places on a trip. The approach to this study is twofold: first several research methods were used to derive the value of time. Second, the use of advanced traveler information is introduced to determine if it plays a critical role in route choice. The proposed methodology shows differences in road user cost calculations. Which approach would be more receptive to a contractor while proposing roadway construction? A case study of a roadway construction project in El Paso, Texas, is used to compare different approaches to calculate road user costs.

Keywords: value of time, work zone, road user cost, dynamic traffic assignment, advanced traveler information.

Corresponding author: Jeffrey Shelton

E-mail: J-Shelton@tti.tamu.edu

This open access article is distributed under a Creative Commons Attribution (CC-BY) 4.0 license. 


\section{Introduction}

When roadways are considered for either rehabilitation or new infrastructure construction, the work zones associated with them typically create disruption to normal traffic flow. This disruption can occur because detours increase the time and distance that must be traveled to complete a trip or because bottleneck areas cause vehicles to operate at less-than-optimal speeds (Barnes \& Langworthy, 2004). Roadway agencies must consider the impact a roadway closure will have on the public versus the costs associated with construction. The total cost of road construction comprises direct costs paid by agencies and indirect costs paid by road users. In densely populated urban areas, work-zone-instigated user costs could outweigh direct costs and therefore need to be considered when examining project alternatives (Dolama et al., 2020).

Time-related contract clauses are primarily designed to encourage contractors through incentives and disincentives to complete construction projects on or ahead of schedule. Highway agencies have gained extensive experience in the application of incentives and disincentives. Agencies typically use road user costs (RUCs) as an economic and legal basis to establish incentives and disincentives. An RUC consists of various components, such as vehicle operating costs (VOCs), vehicle delay costs (VDCs), crash costs, and emission costs. Many agencies have conducted comprehensive studies and developed methodologies to calculate monetary values and evaluate qualitative components of road user costs to aid state departments of transportation (DOTs) in utilizing alternative contracting methods (Sadasivam \& Mallela, 2015).

A substantial amount of literature is available on how to estimate RUCs and establish incentives and disincentives in contracts; however, little guidance exists on calculating RUCs when considering the temporal aspect of traffic congestion coupled with the value of time (VoT) associated with various trip purposes. Most RUC calculations are derived using either historical data or traffic forecasting models. Although these approaches are valid, they fall short of capturing the dynamics of daily traffic conditions (for example, they do not capture the rerouting or diversion of traffic due to various influences). In addition, these types of models use a single VoT for each vehicle class (typically autos or trucks). Driver behavior is influenced by multiple factors, however, and the VoT placed on a trip plays a significant role in route choice and whether a driver is willing to pay a toll to reduce the travel time associated with a specific trip. Advanced traveler information also plays a critical role in driver behavior and the associated route choice taken.

The goal of this research is to derive RUCs that are indicative of actual traffic patterns when sociodemographics are introduced to human behavior. We present a case study from El Paso, Texas, that used a simulation-based dynamic traffic assignment (DTA) model to analyze a work zone closure and how the VoT used for specific trip purposes coupled with advanced traveler information influenced the calculation of RUCs. There are two objectives for this research. First, we derive the VoT for different zones in the city based on socio-economic status. The VoT is weighted based on either the origin zone (socio-economic status) of a trip, or weighting trip purposes defined as the destination zone. Second, we introduce route choice changes based on advanced traveler information and how it influences toll road usage. We utilized a weighting scale for different trip purposes based on departure time.

\section{Literature review}

Multiple agencies have developed methodologies for calculating RUCs. The Federal Highway Administration (FHWA) sponsored a study that provides guidance on considering VOCs, VDCs, emissions costs, and crash costs (Council et al., 2005). The VOC is comprised of fuel and oil consumption, tire wear, maintenance, and mileage-related depreciation. VDCs are determined using FHWA's RealCost Program, which considers traffic volume, work zone capacity, number of queued vehicles, delay times, and flow conditions. Crash costs are associated in terms of crash rates or crash frequency and expressed as the number of crashes per million vehicles for a given roadway section. Crash costs are computed using the following data:

- Crash rate before work zone.

- Crash modification factor (risk escalation).

- Safety improvement countermeasures.

- Estimate of work zone exposure. 
- Estimate unit crash costs (fatal versus nonfatal accidents versus no injury accidents) (Council et al., 2005).

The work zone crash cost is computed by multiplying the work zone crash rate (by crash severity) by the vehicle miles traveled and the corresponding cost per event. The emissions cost is calculated as a function of vehicle miles traveled and unit cost $(\$ /$ ton) by emissions type. The emissions cost component is the differential between the emissions cost resulting from work zone activities and the preconstruction emissions cost (Mallela \& Sadasivam, 2011).

Nadimpalli et al. (2009) utilized an analytical tool (QuickZone) that estimates and quantifies the delays using a simple deterministic queuing model for each roadway link in the work zone. They also used VISUM, a regional travel demand model that assigns volumes on roadways based on a given origindestination matrix. VISUM provides a broader estimation for larger networks. The researchers compared the two approaches to the approximated delay costs calculated by the Utah Department of Transportation's Delay Enhanced (Delay-E) method, which is a deterministic queuing analysis tool that measures traffic flow as it relates to roadway capacity. Results showed that the QuickZone method estimated user delay costs closer to those estimated by the Delay-E method, in which the network was simple and did not include detours. VISUM had lower delay costs than the two alternative methods.

Benekohal et al. (2003) developed the University of Illinois at Urbana-Champaign (UIUC) method, which computes work zone operating speeds from normal operating speeds. Flow rates are computed using speed flow curves that consider the adverse effects of heavy vehicles. The adjusted flow represents the capacity value at which the work zone will operate. After capacity is determined, queue length at the end of every hour is calculated. Finally, delays due to slower speed in the work zone (and stopped queue, if present) are computed.

Studies conducted in Texas have assessed the various practices of RUC calculations for selected work zones. Daniels et al. (1999) identified the key elements of RUCs as used by the Texas Department of Transportation (TxDOT). Their research determined three components in the total equation of calculated RUC, expressed as the summation of VOC, VoT, and accident cost (AC). VOCs include costs for fuel, tires, engine oil, maintenance, and depreciation. ACs are generalized into three different subcomponents: fatal accidents, nonfatal accidents, and property damage only accidents. The VoT component is basically a function of an hourly wage rate multiplied by an average ridership forecast. Daniels et al. noted that, more recently, RUCs in Texas have been included in the calculation of liquidated damages and have been used to verify daily motorist costs for $A+B$ contracts. The following different approaches to determine RUCs in Texas are dependent on project attributes:

Phase-by-Phase - Calculated user costs can be used as the basis for liquidated damages for milestone completions of each phase or selected phases of the project. This approach is most applicable to projects with severe capacity constraints during construction in which phase completion is critical.

Before versus After - Contrary to a phase-by-phase approach, a before versus after comparison of user costs focuses on the delay in final completion of a new or improved facility. Each day construction completion is delayed is another day that users are unable to benefit from travel time savings and other benefits from the addition of roadway capacity.

During Construction versus After Approach - This approach is a combination of the two preceding approaches and is applicable to projects in which the final improvements do not result in an increase in capacity (in other words, rehabilitation projects). The during construction versus after approach compares the user costs associated with lane restrictions during construction against the user costs after the construction is completed.

TxDOT uses two analysis techniques for calculating RUCs-either simulation models or manual estimation. A reference guide was developed to determine when each technique is appropriate for RUC calculation. Simulation models (for example, FREQ, CORSIM, HCS, PASSER, and MicroBENCOST) are used in urban settings for phase-by-phase or before versus after approaches. These models are applicable to high-impact urban freeway construction or rehabilitation and urban arterial roadways (such as diamond interchanges). On the other hand, the manual estimation technique is used in urban or rural settings for either before versus after or during versus after construction approaches. The manual estimation technique is applicable to added capacity projects, rehabilitation, and other noncapacity-added projects (for example, rural highway widening, paving projects, or bridge replacements) (Borchardt \& Voight, 1998; McFarland et al., 1994). 
The approaches outlined in this literature review show various aspects of RUC calculations but fall short of the intricate dynamics of traffic flow throughout the day. We propose a simulation-based dynamic modeling approach that incorporates changes in 24-hour traffic patterns, time-dependent toll rates, and advanced traveler information and incorporates how different VoTs influence RUC rates.

\section{Methodology}

\subsection{Model development and calibration}

A regional planning model of El Paso was initially converted from the metropolitan planning organization's travel demand model (a widely utilized traditional macroscopic model) to a simulationbased DTA model. Macroscopic models are static in nature, meaning they do not convey the dynamics of traffic at any point in time (in other words, there is no clock associated with the model). Macroscopic models simply give averages of performance measures (volume, travel times, delay) over a 24-hour period or a peak travel period. DTA models are simulation based and time dependent, and vehicle interactions are recalculated every six seconds. This process enables users to analyze traffic conditions every minute over a 24-hour period. Figure 1 shows the differences in a 24-hour departure time profile of a macroscopic and mesoscopic model. In addition, macroscopic models are not capacity constrained, so the capacity on heavy congested corridors is fictitiously represented with volume-to-capacity ratios routinely greater than 1 .

Figure 1: Departure time profile-macroscopic versus mesoscopic

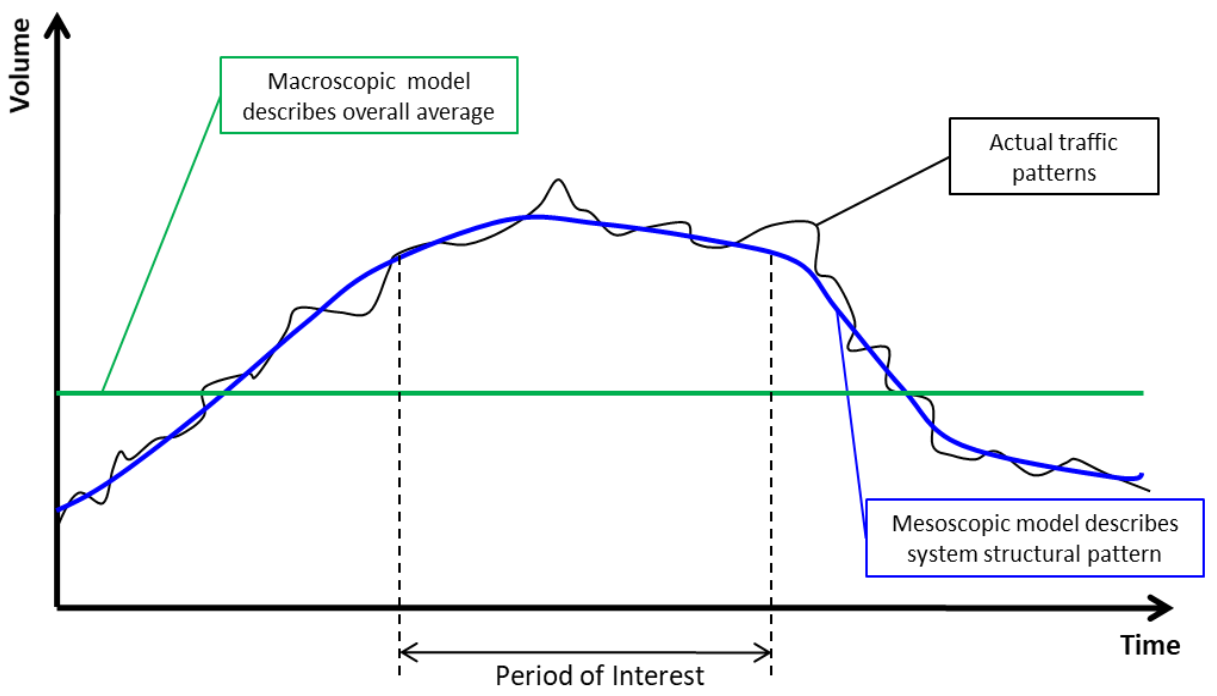

The regional DTA model was calibrated using traffic count data provided by TxDOT. The origindestination (OD) matrices were calibrated using a linearized quadratic minimization problem developed by the University of Arizona in which simulated link counts (volumes) are compared to existing traffic counts (Chiu \& Song, in press). The procedure is an iterative process that alternates between the model and the calibration program. The DTA model was executed with the OD and run to equilibrium conditions. A postprocessing program written in Python was employed to evaluate vehiclebased output data and accumulate information on vehicles (and their associated OD pair) whose paths traversed through any link being evaluated. OD pairs that were found to have vehicles traveling through evaluated links were considered affected OD pairs. The ratio of vehicles from an OD pair that traveled an evaluated link and the total number of vehicles from that same OD pair was calculated. The linear programming solver was then called to determine the optimal number of vehicles to adjust according to the weighted ratios of each affected OD pair. The time-dependent OD demand tables were then rebuilt to reflect the changes, and the demand was fed back into the DTA model to rerun assignment procedures and evaluate the new demand. This action was done in multiple iterations until the convergence criterion was met-which in this case was the minimal total deviation between simulated link volumes 
and actual field counts. Figure 2 depicts the calibration process, while Figure 3 highlights the results of the process after multiple iterations.

Figure 2: OD demand calibration framework

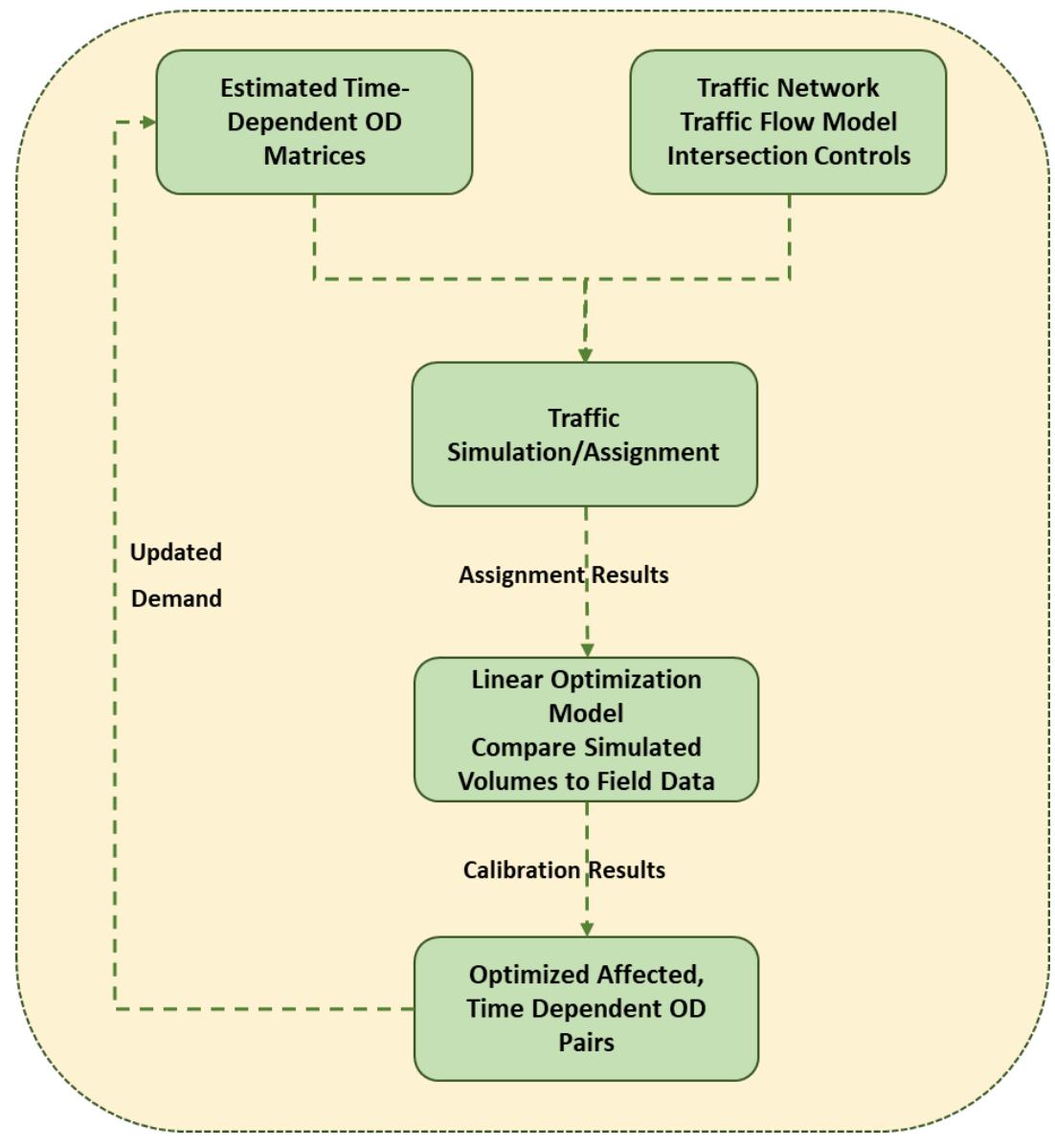

Figure 3: OD calibration-observed versus simulated (auto)

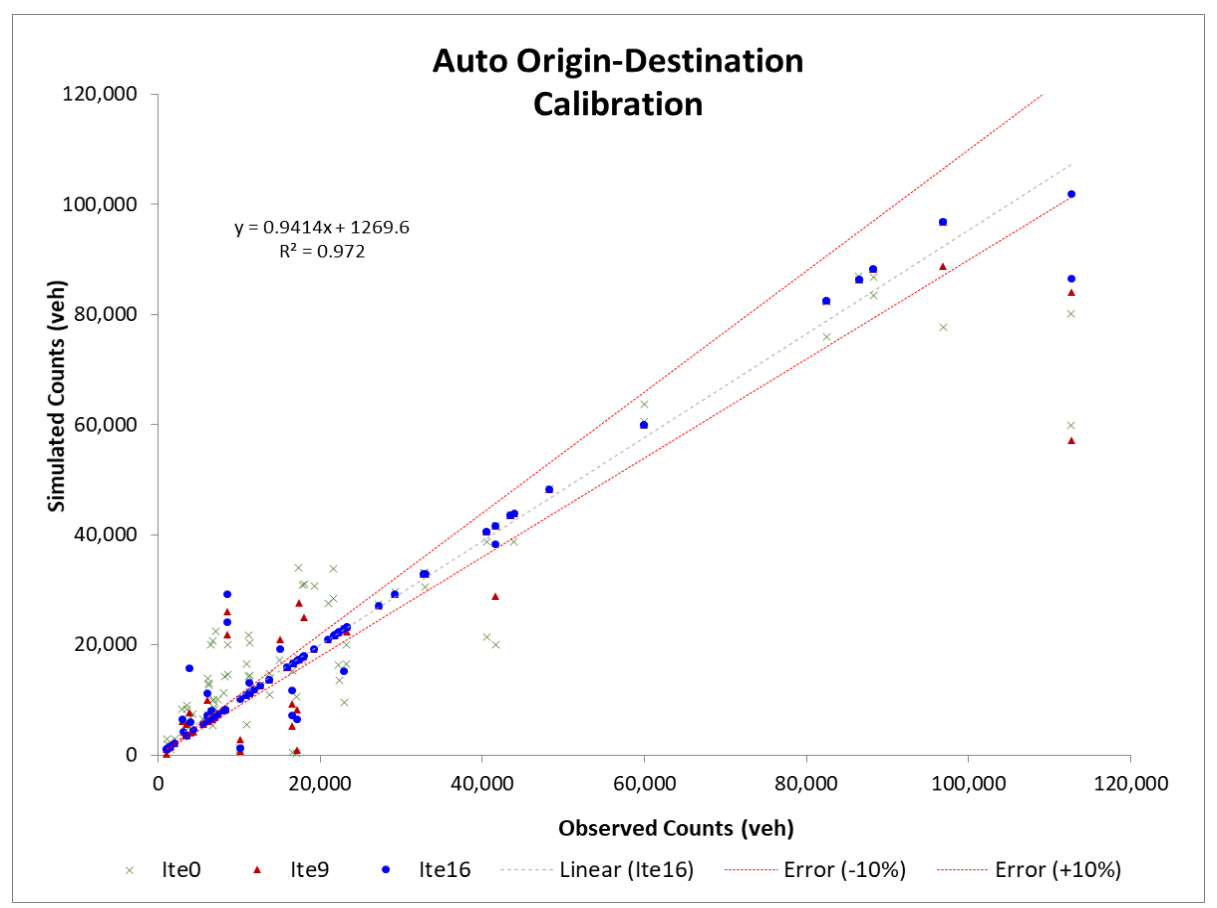


In addition, the traffic flow models were developed and calibrated for both freeway and arterial streets using speed/volume data collected in the field. Traffic counts were converted to flow rates, and the density was calculated using $\mathrm{k}=\mathrm{q} / \mathrm{v}$, where $\mathrm{k}=$ density, $\mathrm{q}=$ flow, and $\mathrm{v}=$ speed. The flow model utilized in the simulation is referred to as the modified Greenshields model, which follows basic traffic engineering principles and relationships of speed, density, and flow (Kachroo \& Ozbay, 2018). Two types of traffic flow models (TFMs) are identified in the time-dependent shortest-path algorithm, as shown in Figure 4 (solid lines show speed-density relationship, whereas dotted lines show flow-density relationship). Type 1 better dictates freeway traffic flow behavior because freeway links have greater capacity than arterials and can hold larger densities near free-flow speeds. Type 2 is more suited for arterial-type links, which are more sensitive to density changes due to interrupted flows (for example, traffic control signals) and less capacity.

Figure 4: Traffic flow model profiles-freeway and arterial streets
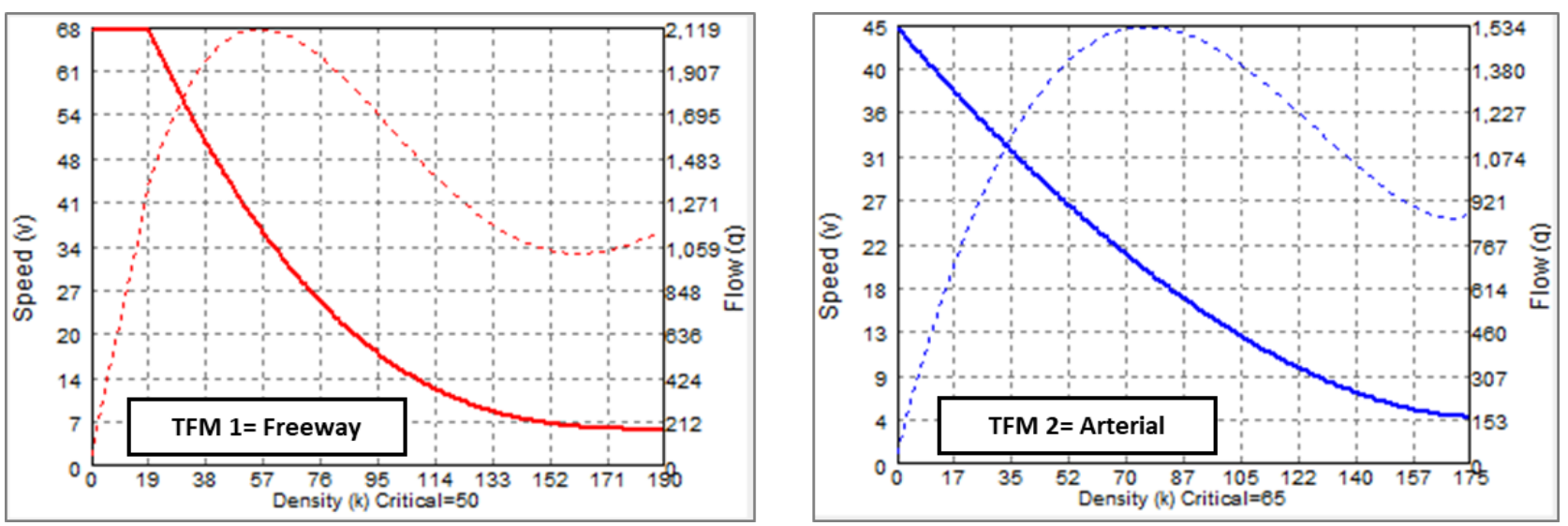

\subsection{Road user cost process}

The VDC and VOC were used as the foundation for determining the overall RUC. The fundamental values used in calculating the VDC were delay, traffic volume on the freeway corridor, and explicit VoT for each vehicle class. Delay was derived from the mesoscopic simulation model and determined by comparing the difference between the ideal travel time (that is, without other vehicles or traffic control) and the mean time delay calculated from all vehicles observed on a specific corridor. The VoT utilized for cars was derived from Shelton et al. (2017), who used a simulation-based model to analyze a tolled facility. They varied the VoT until the amount of auto vehicles simulated on the toll road matched the counts collected by the toll authority. The VoT for autos derived was $\$ 15.77$ per hour. In our study, we used the El Paso metropolitan planning organization's official VoT for trucks $(\$ 45.00)$.

VOCs were constructed using the current price of fuel for cars and trucks, the total fuel consumed, the length of the work zone, the per-mile operating costs for each vehicle class, and the marginal costs per vehicle. Marginal costs included maintenance, tire usage, and depreciation (Barnes \& Langworthy, 2004). The following equations define the entire VDC and VOC process:

$V D C=\left[\left(\gamma_{c}\right)\left(\beta_{c}\right)\left(\alpha_{c}\right)\right]+\left[\left(\gamma_{t}\right)\left(\beta_{t}\right)\left(\alpha_{t}\right)\right]$

where:

$\gamma_{\mathrm{c}}$ : Directional volume for cars through work zone

$\gamma_{t}$ : Directional volume for trucks through work zone

$\beta_{\mathrm{c}}$ : Total delay for cars

$\beta_{\mathrm{t}}$ : Total delay for trucks

$\alpha_{c}$ : Value of time for cars

$\alpha_{t}:$ Value of time for trucks 
$V O C=\left[\left(\omega_{c}\right)\left(\phi_{c}\right)+\left(\omega_{t}\right)\left(\phi_{t}\right)\right]+\theta\left[\left(\tau_{c}\right)\left(\gamma_{c}\right)+\left(\tau_{t}\right)\left(\gamma_{t}\right)\right]$

where:

$\omega_{c}:$ Price of fuel for cars

$\omega_{\mathrm{t}}$ : Price of fuel for trucks

$\mathrm{f}_{\mathrm{c}}$ : Total fuel consumed by cars

$\mathrm{f}_{\mathrm{t}}$ : Total fuel consumed by trucks

$\theta$ : Length of work zone or detour

$\tau_{\mathrm{c}}$ : Per mile operating costs for cars

$\tau_{\mathrm{t}}:$ Per mile operating costs for trucks

$\gamma_{\mathrm{c}}$ : Directional volume for cars through work zone

$\gamma_{\mathrm{t}}$ : Directional volume for cars through work zone

The final RUC equation becomes:

$$
R U C=\sum_{k \in(c, t)}\left(\gamma_{k} \beta_{k} \alpha_{k}\right)+\sum_{k \in(c, t)}\left(\omega_{k} \phi_{k}\right)+\theta \sum_{k \in(c, t)}\left(\tau_{k} \gamma_{k}\right)
$$

\section{Case study}

An RUC case study was conducted on a work zone on Interstate 10 (I-10) in El Paso and examined how the work zone impacted vehicles traveling eastbound-more specifically, trips destined to the University of Texas at El Paso and the central business district. The work zone was part of a large expansion project on I-10. Toll roads were initially constructed to use as a bypass to I-10 on the western portion of El Paso in the event of roadway closure due to incidents, inclement weather, and actual reconstruction of the I-10 main lanes. State Highway (SH) 20 also served as a third alternative route. Figure 5 highlights the location of the eastbound work zone on I-10 and alternative routes.

Figure 5: I-10 work zone location

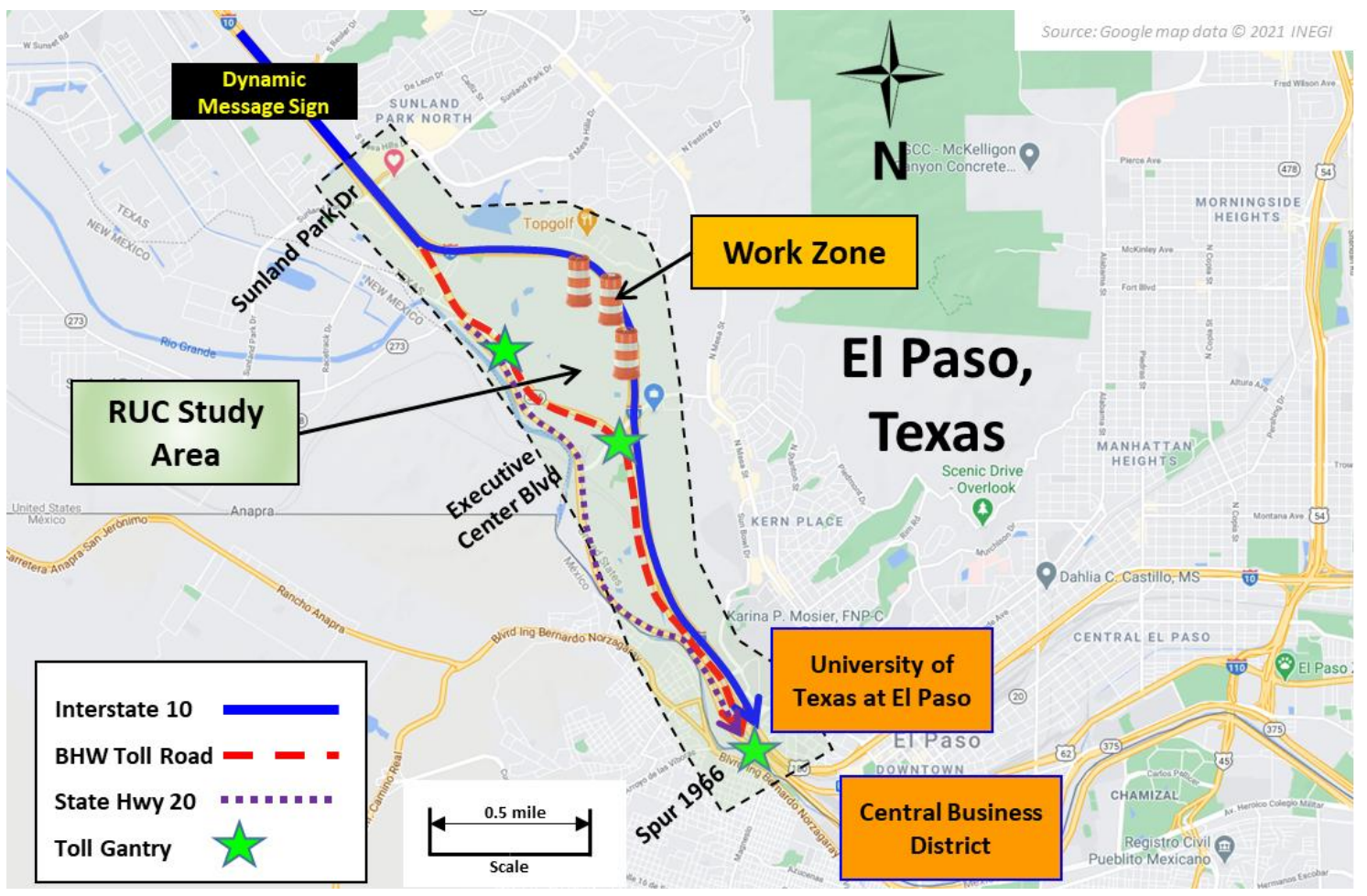


The work zone was a partial closure of I-10 (33 percent capacity reduction), and it was assumed that the closure would be in place for several weeks.

The adjacent Border Highway West (BHW) toll road runs parallel to I-10 for approximately 8 miles and terminates downtown. Three locations on BHW collect tolling fees: (1) the entrance/exit to the University of Texas at El Paso; (2) the entrance/exit ramps at Executive Center Blvd; and (3) further north, the toll gantries directly on the main lanes. The toll road operates 24 hours a day, with different toll rates depending on whether the vehicle is a car or truck and depending on the time of day, as shown in Table 1. SH 20 also runs parallel to I-10/BHW and continues into the downtown area. The RUC study area encompassed I-10, BHW toll lanes, and SH 20 from Sunland Park Dr. to Spur 1966 (approximately 6 miles).

\begin{tabular}{llll}
\begin{tabular}{l} 
Table 1: BHW toll rates \\
\multicolumn{1}{c}{ Tolling Point }
\end{tabular} & \multicolumn{1}{c}{ Time Period } & Cars & Trucks \\
& & & \\
\hline Main Lane Plaza & AM Peak (Mon. - Fri.) $(6: 30 \mathrm{am}-9: 00 \mathrm{am})$ & $\$ 1.27$ & $\$ 5.08$ \\
North of Executive & PM Peak (Mon. - Fri.) $(3: 00 \mathrm{pm}-6: 30 \mathrm{pm})$ & $\$ 1.27$ & $\$ 5.08$ \\
Center Blvd. & Off Peak (Mon. - Fri.) $(9: 00 \mathrm{am}-3: 00 \mathrm{pm} \mathrm{\&} \mathrm{6:30} \mathrm{pm} \mathrm{-} \mathrm{6:30}$ & $\$ 0.64$ & $\$ 2.56$ \\
& am) & $\$ 0.64$ & $\$ 2.56$ \\
Ramps to/from & Weekends (9:00 am - 3:00 pm \& 6:30 pm - 6:30 am) & $\$ 0.86$ & $\$ 3.34$ \\
South at Executive & AM Peak (Mon. - Fri.) $(6: 30 \mathrm{am}-9: 00 \mathrm{am})$ & $\$ 0.86$ & $\$ 3.34$ \\
Center Blvd. & PM Peak (Mon. - Fri.) $(3: 00 \mathrm{pm}-6: 30 \mathrm{pm})$ & $\$ 0.57$ & $\$ 2.28$ \\
& Off Peak (Mon. - Fri.) $(9: 00 \mathrm{am}-3: 00 \mathrm{pm} \mathrm{\&} \mathrm{6:30} \mathrm{pm} \mathrm{-} \mathrm{6:30}$ & & \\
Ramps to/from & am) & $\$ 0.57$ & $\$ 2.28$ \\
South at Spur 1966 & Weekends (9:00 am - 3:00 pm \& 6:30 pm - 6:30 am) & $\$ 0.57$ & $\$ 2.28$ \\
& PM Peak (Mon. - Fri.) (6:30 am - 9:00 am) & $\$ 0.57$ & $\$ 2.28$ \\
& Off Peak (Mon. - Fri.) $(3: 00 \mathrm{pm}-6: 30 \mathrm{pm})$ & $\$ 0.57$ & $\$ 2.28$ \\
& am) & & \\
& Weekends (9:00 am - 3:00 pm \& 6:30 pm - 6:30 am) & $\$ 0.57$ & $\$ 2.28$ \\
\hline
\end{tabular}

Source: Texas Transportation Commission (2020).

A set of scenarios were developed using different VoTs based on origin zone and destination zone. A base model was first constructed based on calibration results. This do-nothing scenario was modeled assuming a typical day with no roadway construction. The first scenario used a single VoT for cars (\$15.77) and trucks (\$45.00), which is the typical approach wherein the VoT remains constant for all vehicles. Time-of-day toll rates, traffic signal timings, TFMs, and defined work zone were all incorporated into the do-nothing model. The model was run to equilibrium, and the results were used as a basis of comparison for subsequent scenarios. Another scenario (SC1) was built off the do-nothing model but incorporated a work zone on I-10 in the western portion of El Paso. SC1 continued to use a single VoT each for cars and trucks.

The next set of scenarios used different VoTs for each traveler-based on either origin sociodemographic or destination trip purpose. A Python script was developed to replace the VoT for each traveler. The base do-nothing model was run to equilibrium conditions. Once the simulation was complete, the model created a trajectory file (trip roster) that included information on each traveler (for example, departure time, originating zone, destination zone, and respective VoT). The single-value VoT was replaced by varied VoTs. The current El Paso regional model includes approximately 2.2 million trips in a 24-hour period.

SC2 was coded using the origin-based VoT. SC2 used the zonal median income in which socioeconomic status defines the VoT. ArcGIS Business Analyst was used to derive the median income per zone. The median income of each zone was divided by 2080 hours, which is the typical number of hours worked in a calendar year. There are 836 traffic analysis zones in the El Paso DTA model. VoTs ranged from $\$ 4.61 /$ hour for the lowest income level zone to $\$ 61.44$ /hour for the highest.

Figure 6 outlines the median income level per zone. 
Figure 6: El Paso median income per traffic analysis zone

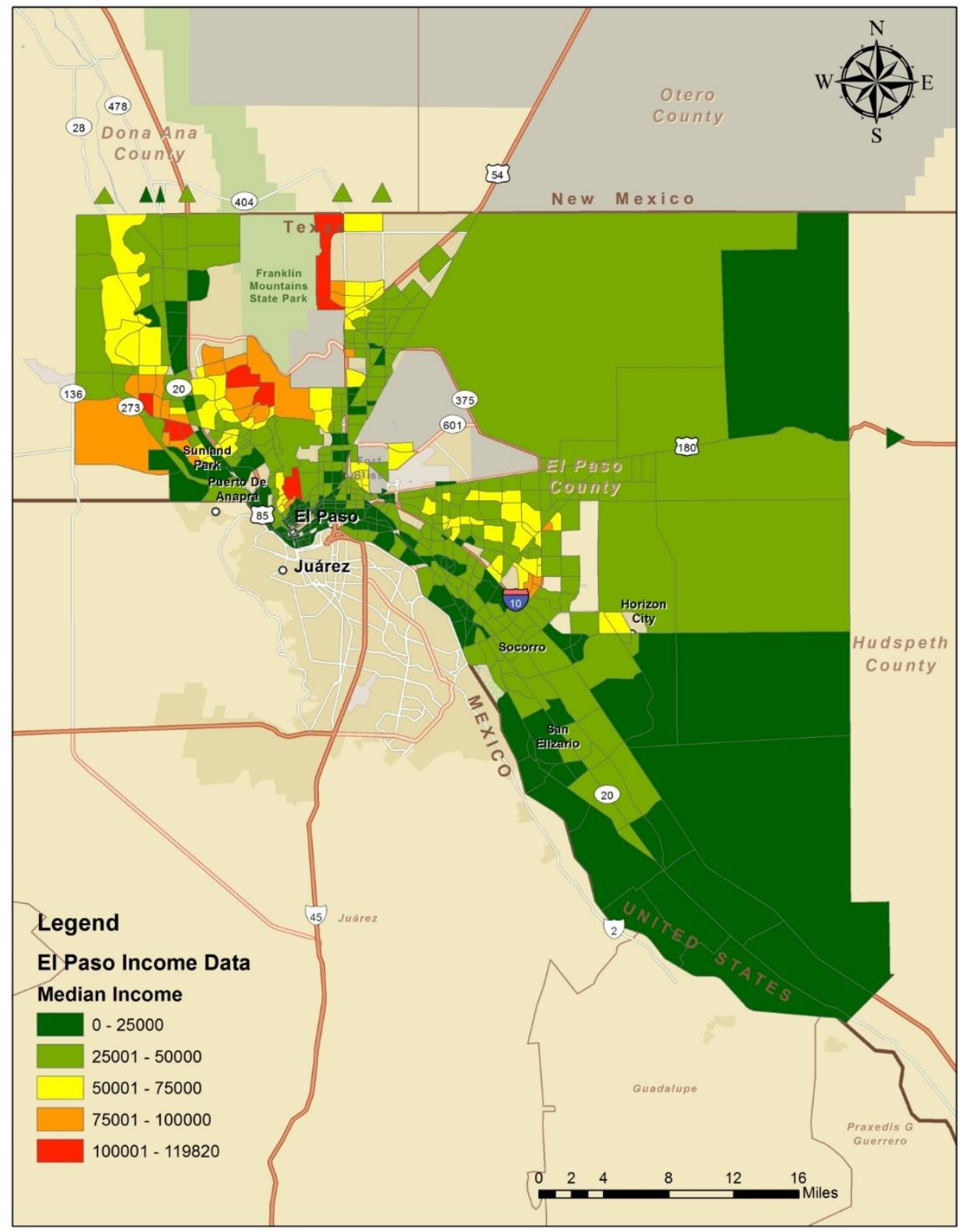

A third scenario (SC3) was developed in which the VoT was defined based on a traveler's destination zone value (in other words, based on the value a driver places on a specific trip purpose). The value a driver places on a trip includes the trip purpose and the departure time of the trip. To derive weighting of trip purposes, a pair-wise comparison exercise was administered to 17 participants. Each participant was given a pair of trip purposes to compare (for example, which is more important-home to work or home to school). Participants were also asked to rank their preference for one trip over another. The scale values used were as follows: $9=$ extremely important, $7=$ very important, $5=$ important, 3 = slightly important, and 1 = equally important. If the alternative trip purpose was favored, the reciprocal values were used. For SC3, each zone was classified based upon the nine trip purposes defined in the El Paso travel demand model, which are as follows:

Home to work $(\mathrm{H}-\mathrm{W})$.

Work to home (W-H).

Home to school (includes college and trips to drop off kids K-12) (H-EDU).

School to home (EDU-H).

Retail - shopping, entertainment, eating out, social, or recreational. 
Other - trips for errands.

Other- 1 - trips to the airport.

Other-2 - trips to medical.

External - trips originating or destinated outside the region (EXT).

These nine different trip purposes were each compared against one another. Work trips warranted the highest weight compared to other trip purposes, while trips for errands (Other) trips had the lowest weight, as shown in Figure 7.

\section{Figure 7: Weighting of trip purposes}

\section{Pair-Wise Comparison of Trip Purpose Weighted Average}

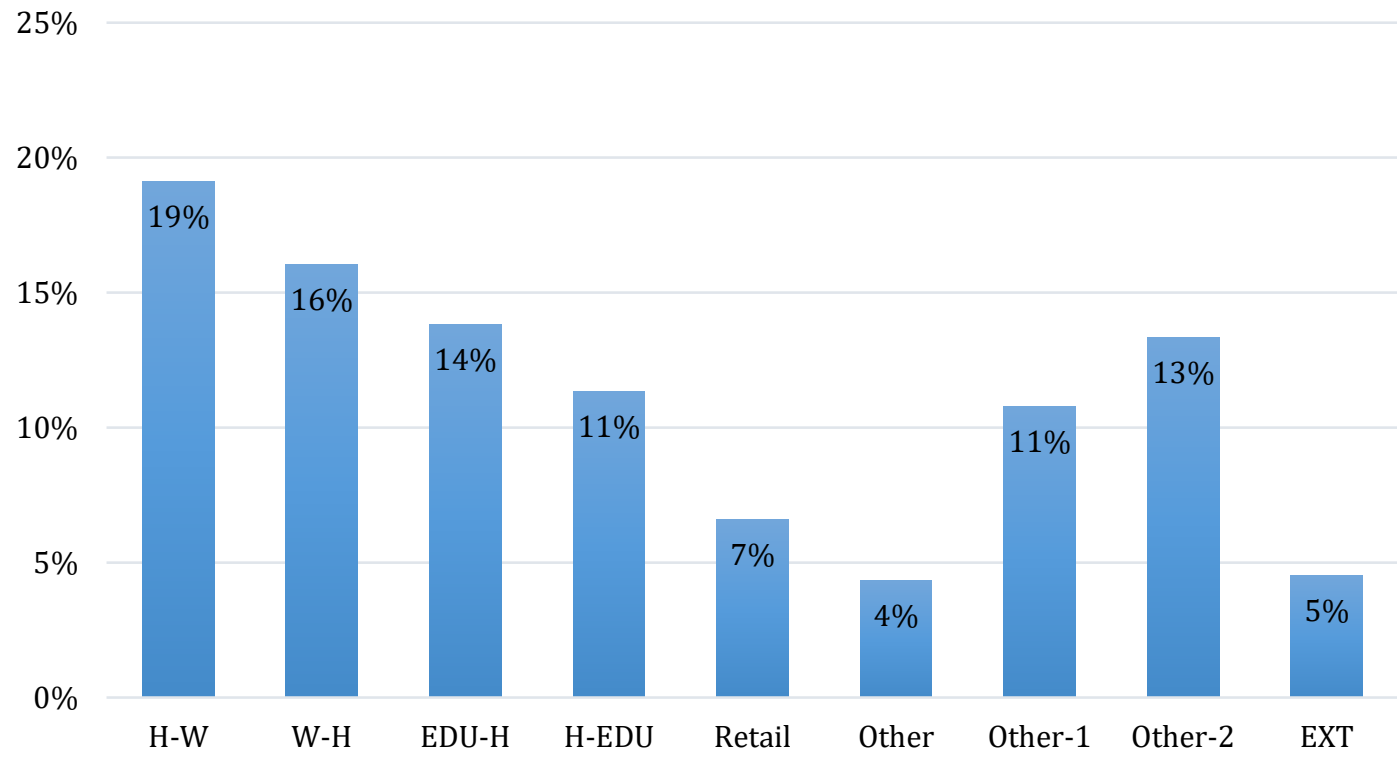

Departure time also contributed to the final weighting of the trip purposes per zone. Diurnal factors from the El Paso travel demand model were applied to the weighting - segregated by hourly departure time. Home-to-work trips that departed in the morning peak periods carried a higher weighting factor than trips leaving later in the day. Final weighting factors for both SC2 and SC3 were used to replace the individual VoT used in SC1.

Advanced traveler information systems (ATISs) are an important component to incorporate into an RUC calculation. However, there is little guidance from the literature regarding how to incorporate this type of information into an RUC study. We used both pre-trip and en route information. Pre-trip information refers to drivers who have information about travel conditions before departure (for example, a driver who watches the news before leaving the house). In the context of a work zone, it is necessary to incorporate having advance information regarding the roadway closure since it will influence driver behavior and the subsequent route chosen.

En route information was also coded into the model-defined as a dynamic message sign (DMS). The DMS provided information about conditions on the road ahead and gave drivers the option to stay on I-10 or divert to the parallel alternate routes. A DMS was coded upstream of the work zone before the junction of I-10 and BHW/SH 20. Advanced traveler information was added to SC2 and SC3, and those scenarios were then termed SC2A and SC3A.

Figure 8 highlights each modeled scenario. A separate scenario that did not include a work zone was also modeled. The no-work-zone scenario was used as the basis of comparison. The RUC calculations were the difference between the no-work-zone versus work-zone scenarios. 
Figure 8: Scenario analysis-methodology flow chart
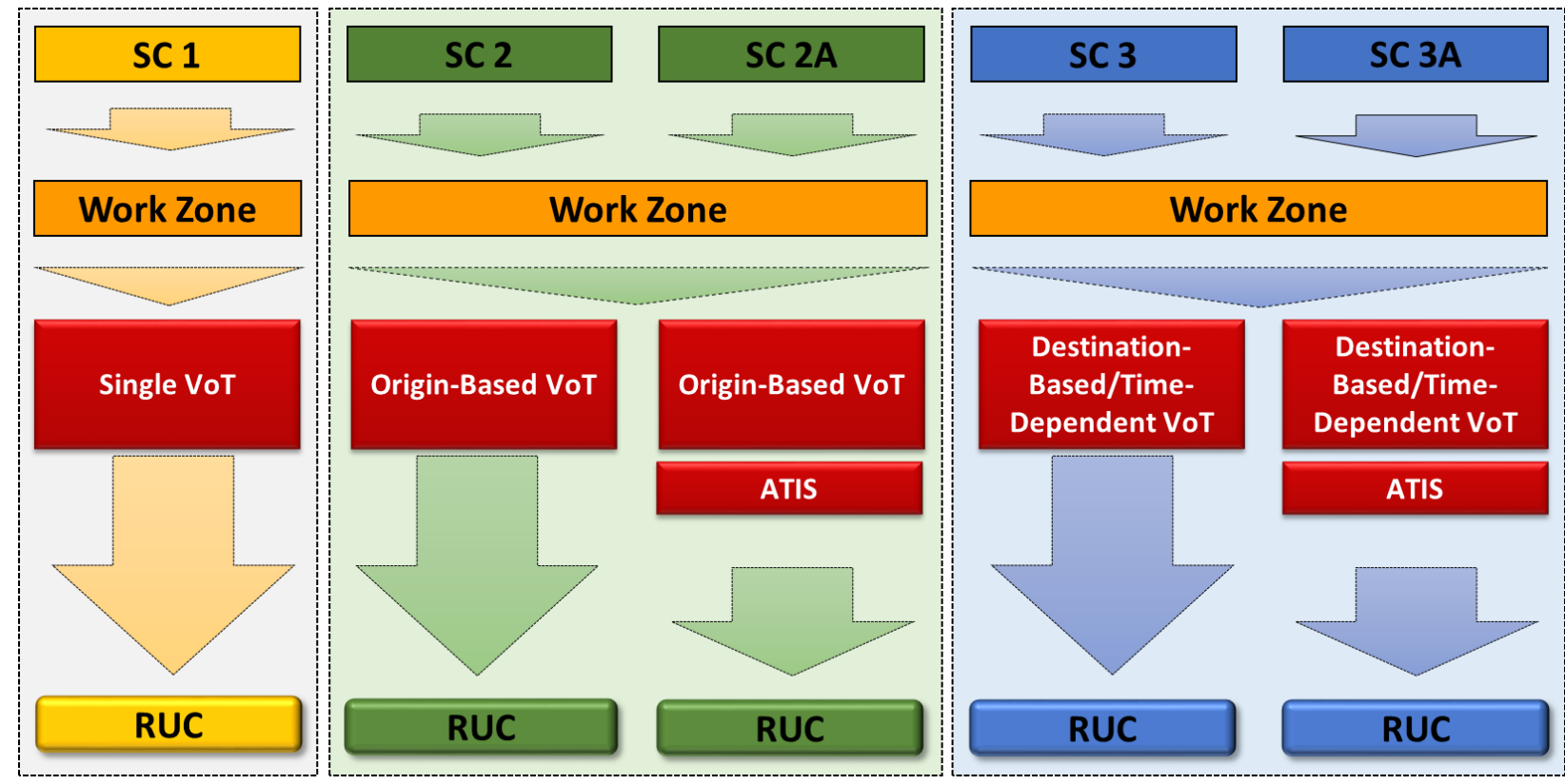

\section{Results}

To capture the dynamics of an ATIS coupled with the VoT and how they impacted the RUC study, measures of effectiveness (MOEs) were collected for the entire El Paso region. This approach considers vehicles re-routing to alternate arterials and collector streets. MOEs for RUC calculations included total volume, total delay encountered, and fuel consumed, as shown in Table 2.

Table 3 shows the amount of traffic that shifts to the two alternate routes.

Figure 9 and Figure 10 show the daily RUC and per person cost respectively.

\begin{tabular}{lccccc}
\multicolumn{2}{l}{ Table 2: Simulation corridor MOEs } \\
Network Stats & Volume & VMT & Delay & Fuel Consumed & Toll Revenue \\
\hline Base & $2,819,210$ & $19,870,133$ & $32,326,986$ & 677,402 & $\$ 518$ \\
SC1 & $2,819,210$ & $20,459,744$ & $41,115,843$ & 684,176 & $\$ 7,912$ \\
SC2 & $2,819,210$ & $19,945,605$ & $40,186,131$ & 682,277 & $\$ 7,240$ \\
SC2A & $2,819,210$ & $19,934,938$ & $40,278,904$ & 682,625 & $\$ 8,565$ \\
SC3 & $2,819,210$ & $19,955,972$ & $39,542,492$ & 682,779 & $\$ 6,230$ \\
SC3A & $2,819,210$ & $19,922,539$ & $40,138,274$ & 680,642 & $\$ 6,368$ \\
\hline
\end{tabular}

\begin{tabular}{|c|c|c|c|c|}
\hline $\begin{array}{l}\text { Corridor } \\
\text { Volumes }\end{array}$ & Volume I-10 & BHW & SH20 & Total \\
\hline Base & 55,250 & 345 & 11,625 & 67,220 \\
\hline SC1 & 18,100 & 7,585 & 34,686 & 60,371 \\
\hline SC2 & 17,715 & 6,553 & 37,906 & 62,174 \\
\hline SC2A & 16,853 & 7,645 & 35,616 & 60,114 \\
\hline SC3 & 16,966 & 5,314 & 38,620 & 60,900 \\
\hline SC3A & 17,400 & 5,261 & 38,224 & 60,885 \\
\hline
\end{tabular}


Figure 9: Daily RUC

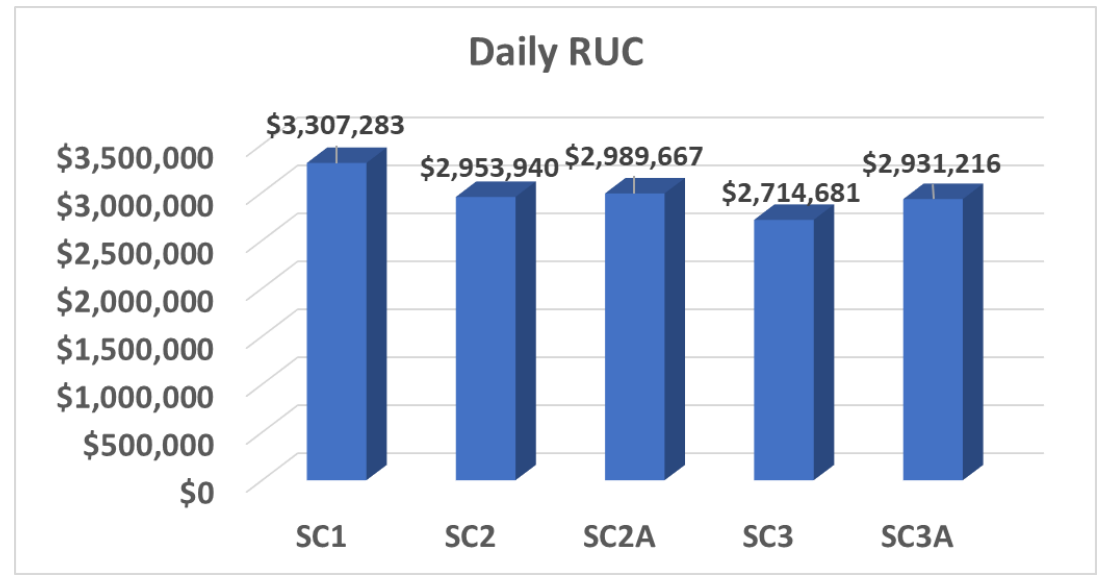

Figure 10: RUC per person

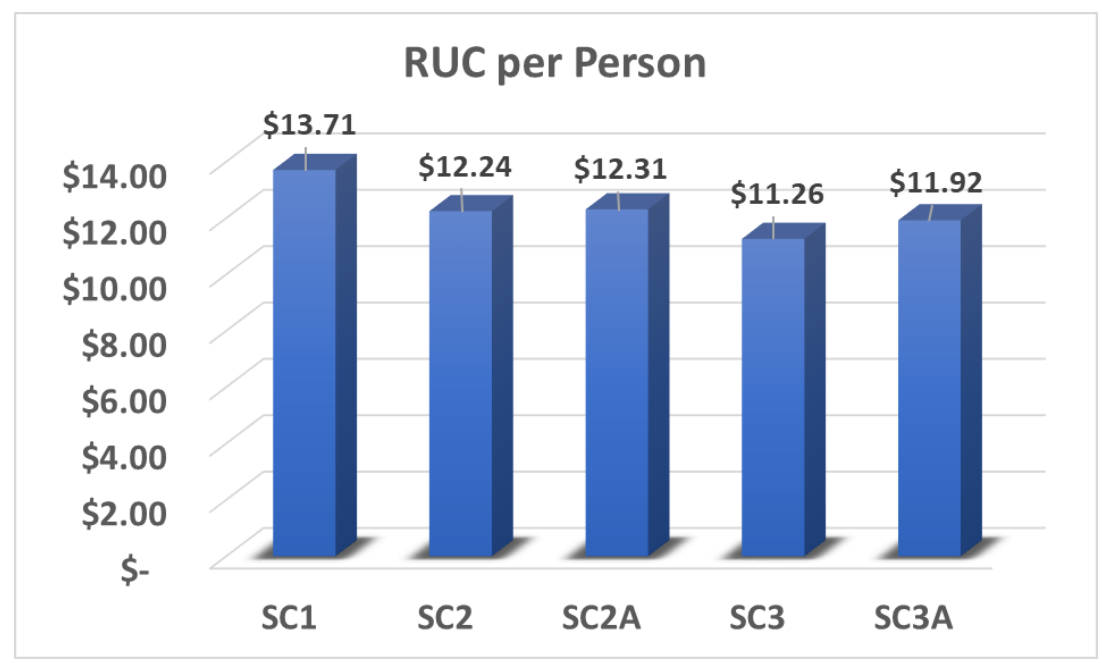

\section{Discussion}

The three modeled approaches showed differences in total and individual RUCs. SC1 which uses a single VoT showed the highest RUC which is attributed to the highest delay and fuel consumption. The origin-based VoT (SC2) approach uses the median income per zone. While each traveler has a different VoT based on socio-economic status, the main contributing factors that influence route choice are the congestion levels contributed by the work zone and the time of day toll rates. When the ATIS is introduced to SC2A, there is slightly less traffic using the three alternate facilities combined, but a higher volume on the toll facility. This indicates that the advanced information has an influence on a driver's willingness to pay a toll to reduce travel time.

The destination-based VoT (SC3), which is based on trip purpose, had the lowest total RUC. Assigning VoT based on trip purpose provides the greatest improvement in overall traffic congestion as shown by the lowest overall total delay. This scenario shows that trip purpose has a lower overall influence on route choice as it pertains on an individual's willingness to pay a toll to improve travel time. Once we introduced ATIS to SC3A, the model results showed slightly higher diversion to BHW-but lower than the origin-based VoT approach.

\section{Conclusion}

Several approaches for calculating RUCs with the introduction of socioeconomics and advanced traveler information are outlined herein. This methodology highlights the use of a simulation-based DTA model. The main advantage to using this type of model is its ability to reroute vehicles on a timedependent basis. Travel demand models (macro models) are not simulation based, so they do not have 
a concept of time. Macro models are not capacity constrained, so they can route more vehicles on a corridor than is physically possible. Micro models, on the other hand, are capacity constrained. However, they cannot reroute vehicles to all alternate paths simply because they are limited to a smaller geographic region (in other words, it is too difficult and labor intensive to build a regional or citywide microscopic model). In addition, micro models assign a route to travelers immediately at the onset of their trip and do not consider route diversion during their trip, so it is impossible to incorporate different VoTs and pre-trip and en route information into a traveler's route choice. The VoT placed on a trip has a substantial influence on whether a traveler elects to pay for a tolled facility to improve travel time. In addition, ATIS also plays a role in route choice. Thus, DTA models are best suited for this type of analysis because of their ability to incorporate different types of information.

The pair-wise comparison study highlights the value travelers place on one trip purpose versus another. Travelers journeying to and from home to work, school, and the airport had a higher VoT, thus making them more inclined to pay for a toll road. However, this study highlights a driver's willingness to pay for a toll when the VoT is weighted by trip purpose as outlined in the pair-wise comparison study. SC3 and SC3A both showed lower toll revenue indicating that trip purpose has a lower influence on toll road utilization than origin-based socio-economics. It also showed that the destination-based VoT will influence more utilization of arterials and collector streets-thus making the three main travel corridors less attractive.

This research outlines an innovative way to calculate RUCs. Several different approaches used to calculate the VoT placed on a trip were introduced which poses the question-which one is correct? If the single VoT approach yields the highest RUC, would a department of transportation choose that option? Further research should address how unforeseen circumstances (e.g., traffic accidents) influence route choice. It is important to note that this approach assumes that a traveler's departure time is fixed. ATIS will undoubtedly influence departure time for travelers. Thus, future research will include the ability for travelers to update their respective departure time. Finally, this research only modeled the work zone in one direction (eastbound) which accommodates the morning peak period. Incorporating a work zone in the opposite direction as well will certainly influence route choice during the afternoon peak period when a high percentage of trips are work to home.

\section{Citation information}

Shelton, L., \& Martin, P. T. (2021). How does the value of time influence road user costs during work zone closures? A case study in El Paso, Texas, using simulation-based modeling methods. Journal of Sustainable Development of Transport and Logistics, 6(1), 18-31. doi:10.14254/jsdtl.2021.6-1.2.

\section{References}

Barnes, G., \& Langworthy, P. (2004). Per mile costs of operating automobiles and trucks. Transportation Research Record: Journal of the Transportation Research Board, 1864, 71-77. https://doi.org/10.3141/1864-10

Benekohal, R., Kaja-Mohideen, A., \& Chitturi, M. (2003). Evaluation of construction work zone operational issues: Capacity, queue and delay (Report No. ITRC FR 00/01-4). Illinois Transportation Center, Illinois Department of Transportation.

Borchardt, D., \& Voight, A. (1998). A short course on techniques for determining construction related road user costs. Texas Transportation Institute.

Chiu, Y.-C., Zhou, L., \& Song, H. (2010) The development and calibration of the Anistropic Mesoscopic Simulation Model on uninterrupted flow facilities. Transportation Research, Part B: Methodological.

Council, F., Zaloshnja, E., Miller, T., \& Persaud, B. (2005). Crash cost estimates by maximum policereported injury severity within selected crash geometries (Report No. FHWA-HRT-05-051). Federal Highway Administration.

Daniels, G., Ellis, D., \& Stockton, W. (1999). Techniques for manually estimating road user costs associated with construction projects. Texas Transportation Institute. 
Dolama, M., Falls, L., \& Regehr, J. (2020). Probabilistic methodology to quantify user delay costs for urban arterial work zones. Journal of Transportation Engineering, Part A: Systems, 146. https://doi.org/10.1061/JTEPBS.0000424

Kachroo, P., \& Ozbay, K. M. A. (2018). Feedback control theory for dynamic traffic assignment (2nd ed.). Springer International. http://doi.org/10.1007.978-3-319-69231-9_3

Mallela, J., \& Sadasivam, S. (2011). Work zone road user costs: Concepts and applications (Report No. FHWA-HOP-12-005). Applied Research Associates.

McFarland, W., Kabat, R., \& Krammes, R. (1994). Comparison of contracting strategies for reducing project construction time. Texas Transportation Institute.

Nadimpalli, B., Martin, P., Chaudhuri, P., \& Stevanovic, A. (2009). Road user impacts due to speed limit reduction in work zones-Which tool is best: QuickZone or VISUM [Paper presentation]. Transportation Research Board 89th Annual Meeting, Washington, DC. https://www.workzonesafety.org/files/documents/database_documents/TRB2010paper_Nadim palli.pdf

Sadasivam, S., \& Mallela, J. (2015). Application of work zone road user costs to determine schedulerelated incentives and disincentives: Conceptual framework. Transportation Research Record: Journal of the Transportation Research Board, 2504, 39-45. https://doi.org/10.3141/2504-05

Shelton, J., Martin, P. T., \& Valdez, G. (2017). Deriving the value of time in a border region using a state-ofthe-art dynamic modeling approach [Paper presentation]. European Transport Conference, Barcelona, Spain. $\quad$ https://aetransport.org/past-etc-papers/conference-papers2017?abstractId $=5712 \&$ state $=b$

Texas Transportation Commission. (2020). Minute order: Border Highway West Expressway toll rates. https://ftp.dot.state.tx.us/pub/txdot/commission/2019/1031/13d2.pdf

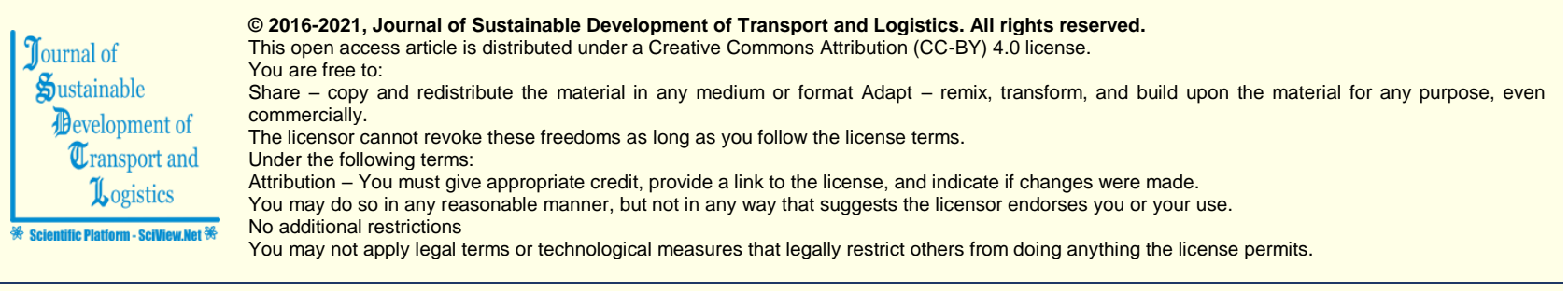

Journal of Sustainable Development of Transport and Logistics (ISSN: 2520-2979) is published by Scientific Publishing House "CSR", Poland, EU and Scientific Publishing House "SciView", Poland, EU

Publishing with JSDTL ensures:

Publishing with JSDTL ensures:
Immediate, universal access to your article on publication

- High visibility and discoverability via the JSDTL website

- Rapid publication

- Rapid publication

- Discounts and waivers for authors in developing regions

Submit your manuscript to a JSDTL at https://jsdtl.sciview.net/ or submit.jsdt|@sciview.net 